\title{
Density Functional Theory Study of the Partial Oxidation of Methane to Methanol on Au and Pd Surfaces
}

\author{
Ali Nasrallah ${ }^{1}$, Julien Engel ${ }^{1}$, C. Richard A. Catlow ${ }^{1,2}$ and David J. Willock ${ }^{1^{*}}$
}

(1) Max Planck-Cardiff Centre on the Fundamentals of Heterogeneous Catalysis FUNCAT, Cardiff Catalysis Institute, School of Chemistry, Cardiff University, Main Building, Park Place, Cardiff, CF10 3AT, United Kingdom.

(2) Department of Chemistry, University College London, 20 Gordon St., London, WC1 HOAJ, United Kingdom.

* author to whom correspondence should be addressed willockdj@cardiff.ac.uk.

\section{Supplementary Information:}

\section{S1 Methodology}

The face centred cubic (fcc) bulk structures of both Au and Pd were initially optimised using the ISIF $=3$ command which allows us to alter all three degrees of freedom (position of the atoms, cell shape, and cell volume). Once optimised, the DFT unit cell dimensions were used as the basis for defining slab models of the surfaces of $\mathrm{Au}$ and Pd. Since structural examination of the Au-Pd alloy colloids revealed that the nanoparticles produced experimentally have mostly icosahedral structures with some cuboctahedral characteristics, we modelled the (111) and the (100) surface facets. These were cut from the optimised bulk structures and expanded to form large surface area slab models of the metal surfaces. Figure S1 shows the structure of the surfaces used.

In order to avoid interactions between adjacent slabs, a sufficient vacuum gap has to be introduced above the highest layer. Therefore, the vacuum thickness needs to be

a)

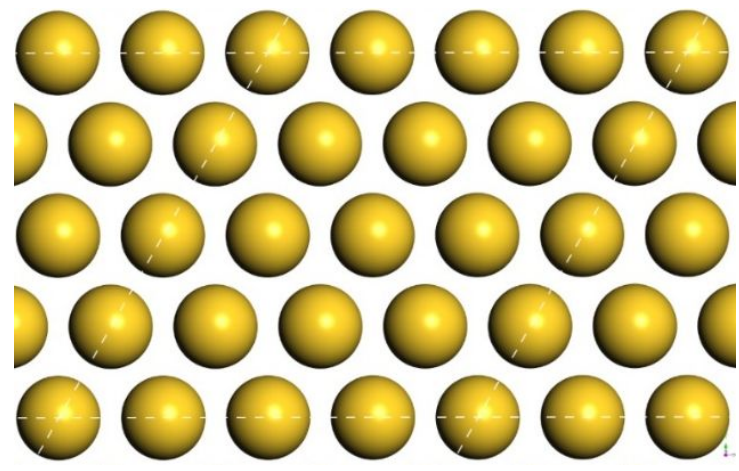

b)

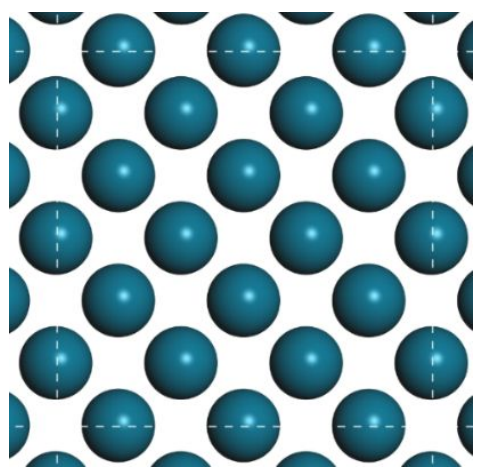

Figure S1: Surface structure of 5-layer simulation slabs, a) 80-atom slab model of $\mathrm{Au}(111)$ and $b) 90$-atom slab model of $\operatorname{Pd}(100)$. Simulation cell periodic boundaries are shown as white dotted lines in each case. Atom colours: Au; yellow and $\mathrm{Pd}$; blue. 
increased until the value of the surface energy becomes constant. The surface energy was computed using equation S1.

$$
E_{\text {surf }}=\frac{E_{\text {slab }}-\left(n \times E_{\text {bulk }}\right)}{2 \times S}
$$

Where $E_{\text {slab }}$ is the electronic energy of the slab, $\mathrm{n}$ is the ratio of the number of atoms in the slab to the number of atoms in the bulk, $E_{\text {bulk }}$ is the electronic energy of the bulk and $S$ is the surface area of the surface.

As shown in figure $\mathrm{S} 1$, the shape of the (100) surface simulation cell is a square and thus the surface area is equal to the square of the lattice constant. The area, $S_{(111)}$, of the (111) surface can be calculated as the area of a parallelogram:

$$
S_{(111)}=a b \sin \gamma
$$

Where $a$ and $b$ correspond the dimensions of the surface lattice vectors and $\gamma$ is the angle between the two vectors.

The benchmarking for the vacuum gap was performed without D3-dispersion and with all atoms in the simulation slab optimised so that equation S1 could be applied. Table S1 shows the surface energy for the different vacuum gaps tested. There is very little variation in the surface energy with respect to the varying size of the vacuum gap for all surface. Even though the surface energy is constant, the vacuum gap needs to be large enough in order to accommodate the adsorbate and avoid Van der Waals interactions between the periodically repeated slabs in the $z$-direction. Thus, throughout this work, a vacuum gap size of $13 \AA$ was used. The surface energy of the (111) surface for both metals is lower than that of the (100) surface suggesting that the (111) surface is more stable. This is expected as the number of neighbouring atoms for each atom in the (111) surface is greater than that in the (100).

Generally, the surface structures used to simulate reactions had some lower layers frozen at their relaxed bulk positions. In this case the surface energy calculation is adapted to use the equation:

$$
E_{\text {surf }}=\frac{E_{\text {slab }}-n E_{\text {bulk }}}{S}-E_{\text {surf }}^{\text {term }}
$$


where $E_{\text {surf }}^{\text {term }}$ is the surface energy calculated using equation S1 for the slab with all atoms fixed at their bulk positions. Equation S3 gives the relaxed surface energy taking into account that the lower surface of the slab is now not equivalent and has the surface energy of the truncated bulk.

The layers that are allowed to move and which are to remain fixed was controlled using the "selective dynamics" tag in the input (POSCAR) file. Thus, to ensure that the upper surface of the slab model is relaxed while retaining the bulk character of the lower layers, benchmark structural optimisation calculations with a varying number of relaxed layers were performed. In order to determine the effect of dispersion correction on the surface energy, the benchmarking was also performed with D3-dispersion included. Table S2 shows the surface energy variation with number of fixed layers for the four surfaces. There is very little variation in the surface energy with respect to number of relaxed layers. The calculated surface energy is converged to $0.01 \mathrm{~J} \mathrm{~m}^{-2}$ at 2 relaxed layers in all cases. Accordingly, modelling of the reaction elementary steps were carried out with the top two layers relaxed and the bottom three fixed. 
Table S1: Surface energy with varying vacuum gap sizes without D3-dispersion.

\begin{tabular}{|c|c|c|c|c|}
\hline$\underset{\AA}{\text { Vacuum gap / }}$ & $\begin{array}{c}\mathbf{A u}(111) \\
E_{\text {surf }} \\
\mathbf{J} \mathbf{~ m}^{-2}\end{array}$ & $\begin{array}{c}\mathbf{A u}(\mathbf{1 0 0}) \\
E_{\text {surf }} \\
\mathbf{J} \mathbf{~ m}^{-2}\end{array}$ & $\begin{array}{c}\text { Pd(111) } \\
E_{\text {surf }} \\
\mathrm{J} \mathrm{m}^{-2}\end{array}$ & $\begin{array}{c}\text { Pd(100) } \\
E_{\text {surf }} \\
\mathrm{J} \mathrm{m}^{-2}\end{array}$ \\
\hline 7 & 0.694 & 0.851 & 1.328 & 1.540 \\
\hline 8 & 0.695 & 0.850 & 1.328 & 1.541 \\
\hline 9 & 0.695 & 0.848 & 1.328 & 1.540 \\
\hline 10 & 0.695 & 0.848 & 1.327 & 1.540 \\
\hline 11 & 0.694 & 0.847 & 1.327 & 1.540 \\
\hline 12 & 0.694 & 0.847 & 1.326 & 1.540 \\
\hline 13 & 0.693 & 0.846 & 1.325 & 1.539 \\
\hline 14 & 0.693 & 0.846 & 1.325 & 1.539 \\
\hline 15 & 0.693 & 0.846 & 1.325 & 1.538 \\
\hline
\end{tabular}

Table S2: Surface energy variations with varying number of relaxed layers

\begin{tabular}{ccccc}
\hline $\begin{array}{c}\text { No. of } \\
\text { relaxed } \\
\text { layers }\end{array}$ & $\begin{array}{c}\mathbf{A u}(\mathbf{1 1 1}) \\
\boldsymbol{E}_{\text {surf }}\end{array}$ & $\begin{array}{c}\mathbf{A u}(\mathbf{1 0 0}) \\
\mathbf{E}_{\text {surf }} \\
/ \mathbf{J ~ m}^{-2}\end{array}$ & $\begin{array}{c}\mathbf{P d}(\mathbf{1 1 1}) \\
\boldsymbol{E}_{\text {surf }} \\
/ \mathbf{J ~ m ~}^{-2}\end{array}$ & $\begin{array}{c}\mathbf{P d}(\mathbf{1 0 0}) \\
\boldsymbol{E}_{\text {surf }} \\
/ \mathbf{J ~ m}^{-2}\end{array}$ \\
\hline $\mathbf{1}$ & 1.427 & 1.548 & 2.122 & 2.300 \\
$\mathbf{2}$ & 1.414 & 1.548 & 2.112 & 2.300 \\
$\mathbf{3}$ & 1.413 & 1.548 & 2.112 & 2.300 \\
$\mathbf{4}$ & 1.409 & 1.545 & 2.109 & 2.299 \\
$\mathbf{5}$ & 1.409 & 1.545 & 2.109 & 2.299 \\
\hline
\end{tabular}

Table S3: Convergence of Bader charges with VASP grid settings. ${ }^{a}$

\begin{tabular}{ccccc}
\hline $\begin{array}{c}\text { ngx, ngy } \\
\text { (ngxf, ngxf) }\end{array}$ & ngz (ngzf) & $\begin{array}{c}\text { Grid spacing } \\
\boldsymbol{x}, \boldsymbol{y}(\boldsymbol{z}) \\
/ \boldsymbol{\AA}\end{array}$ & $\begin{array}{c}\boldsymbol{q}_{d}(\mathbf{O H})^{\boldsymbol{b}} \\
/|\boldsymbol{e}|\end{array}$ & $\begin{array}{c}\boldsymbol{q}_{\boldsymbol{a}}(\mathbf{O H})^{\boldsymbol{b}} \\
/|\boldsymbol{e}|\end{array}$ \\
\hline $60(120)$ & $160(320)$ & $0.137(0.132)$ & -0.3735 & -0.4674 \\
\hline $164(328)$ & $424(848)$ & $0.050(0.050)$ & -0.3754 & -0.4665 \\
\hline $205(410)$ & $530(1060)$ & $0.040(0.040)$ & -0.3751 & -0.4667 \\
\hline $234(468)$ & $605(1210)$ & $0.035(0.035)$ & -0.3752 & -0.4670 \\
\hline $273(546)$ & $706(1412)$ & $0.030(0.030)$ & -0.3751 & -0.4669 \\
\hline
\end{tabular}

Notes: $a$ ) The test system was the dissociated $\mathrm{H}_{2} \mathrm{O}_{2}$ structure on $\mathrm{Au}(100)$ shown as inset on Figure 2 in the main text. $b) q_{a}(\mathrm{OH}) / q_{d}(\mathrm{OH})$ refer to the calculated charges on the acceptor/donor $\mathrm{OH}$ groups in the hydrogen bond formed in the structure, $\mathrm{OH}_{d} \ldots \mathrm{OH}_{a}$. 
To assess the charge state of atomic species and groups in these calculations we have used the Bader analysis ${ }^{1}$ approach as implemented for VASP CHGCAR files by the Henkleman group. ${ }^{2,3,4}$ Table S3 shows a series of calculations for the case of dissociated adsorption of $\mathrm{H}_{2} \mathrm{O}_{2}$ on $\mathrm{Au}(100)$ ( structure shown as inset on Figure 2) with the total charge assigned to the two $\mathrm{OH}$ groups given for different settings of the real space grid used to hold the charge density. It should be noted that these calculations have been carried out without the ADDGRID keyword in the VASP input files. This option is provided to improve force accuracy during optimisation of structures but was found to lead to poor convergence of the Bader charges with respect to grid settings. To represent the charge density VASP uses a normal grid and a fine grid defined by user parameters giving the number of grid points along each cell vector, $n g x, n g y$ and $n g z$, for the normal grid and $n g x f, n g y f$ and $n g z f$ for the fine grid. In our example, the $a$ and $b$ vectors are both $8.1912 \AA$ while the $c$ vector defines the vacuum gap and so is much longer at $21.1876 \AA$. The default program settings give a 60 points along each of $a$ and $b$ and 120 along $c$ with the fine grid having 120 along $a$ and $b$ and 320 along $c$. Table S3 shows that, in this test case, increasing the number of grid points to 205 along $a$ and $b$ and 530 along $c$ while maintaining a fine grid at twice this point density gives is sufficient to obtain charges converged to $10^{-3}|e|$. This corresponds to a grid spacing of $0.04 \AA$ which has been used throughout our charge analysis calculations. 


\section{S2 Results}
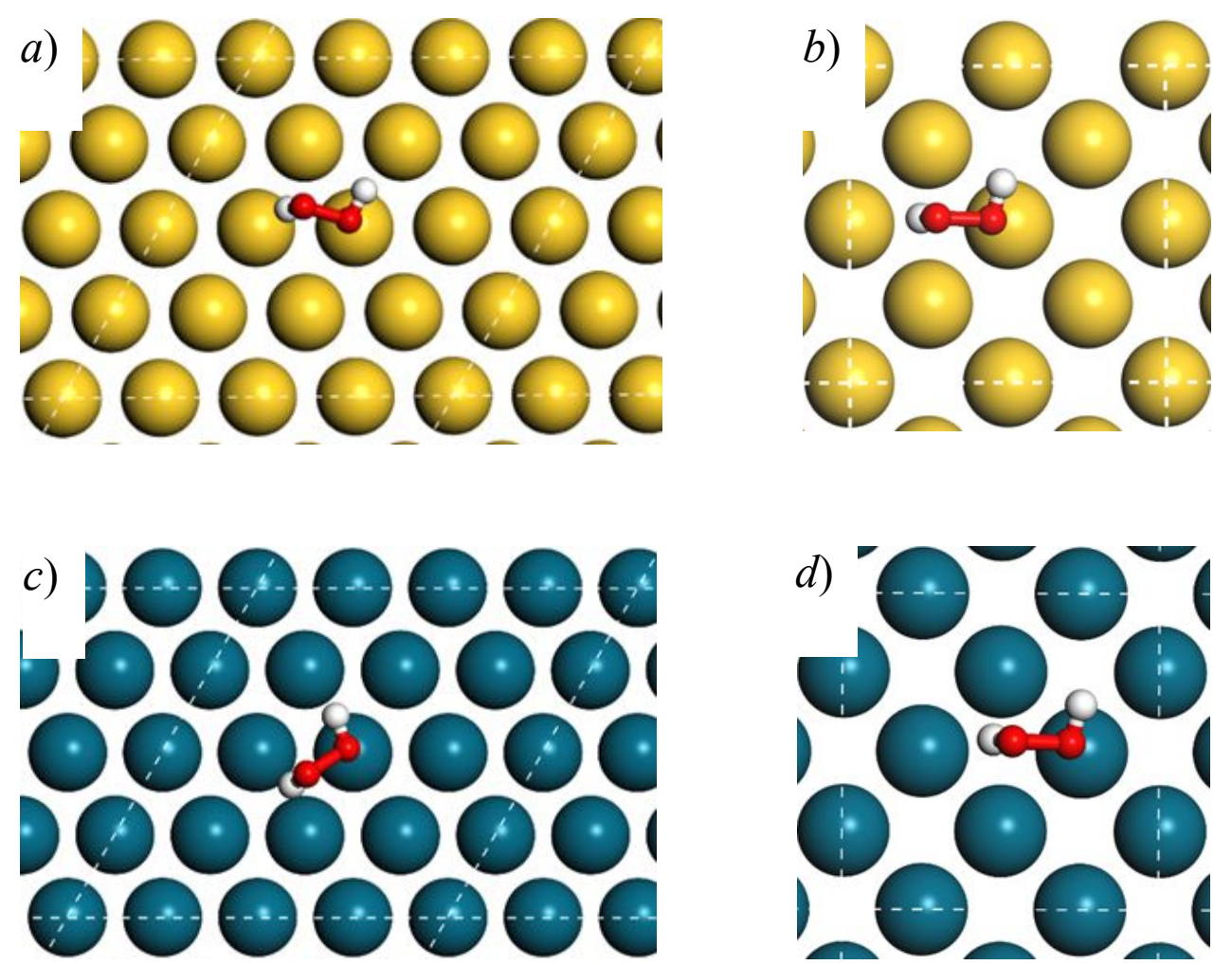

Figure S2: Optimised geometry for the molecular adsorption of $\mathrm{H}_{2} \mathrm{O}_{2}$ to a) $\mathrm{Au}(111)$, b) $\mathrm{Au}(100), c) \mathrm{Pd}(111)$ and d) $\mathrm{Au}(100)$. Atom colours: Au; yellow, Pd; blue, O; red and $\mathrm{H}$; white.

Table S4: Bader charges for $\mathrm{OH}$ groups produced on dissociation of $\mathrm{H}_{2} \mathrm{O}_{2}$.

\begin{tabular}{|c|c|c|c|c|}
\hline & $\begin{array}{c}q_{d}(\mathbf{O H})^{a} \\
/|| e \mid\end{array}$ & $\begin{array}{c}q_{a}(\mathbf{O H})^{a} \\
/ /|e|\end{array}$ & $\begin{array}{c}\mathrm{OH}_{d \ldots \mathrm{O}}(\mathrm{H})_{a} \\
/ \AA\end{array}$ & $\begin{array}{c}q_{d}(\mathrm{OH})-q_{a}(\mathrm{OH}) \\
/|e|\end{array}$ \\
\hline $\mathrm{Au}(111)$ & -0.396 & -0.482 & 1.837 & 0.086 \\
\hline $\mathrm{Au}(100)$ & -0.375 & -0.467 & 1.788 & 0.092 \\
\hline $\operatorname{Pd}(111)$ & -0.358 & -0.439 & 1.933 & 0.081 \\
\hline $\operatorname{Pd}(100)$ & -0.345 & -0.452 & 1.752 & 0.107 \\
\hline
\end{tabular}

Note: $a) q_{a}(\mathrm{OH}) / q_{d}(\mathrm{OH})$ refer to the calculated charges on the acceptor/donor $\mathrm{OH}$ groups in the hydrogen bond formed in the structure, $\mathrm{OH}_{d} \ldots \mathrm{O}(\mathrm{H})_{a}$. 
a)

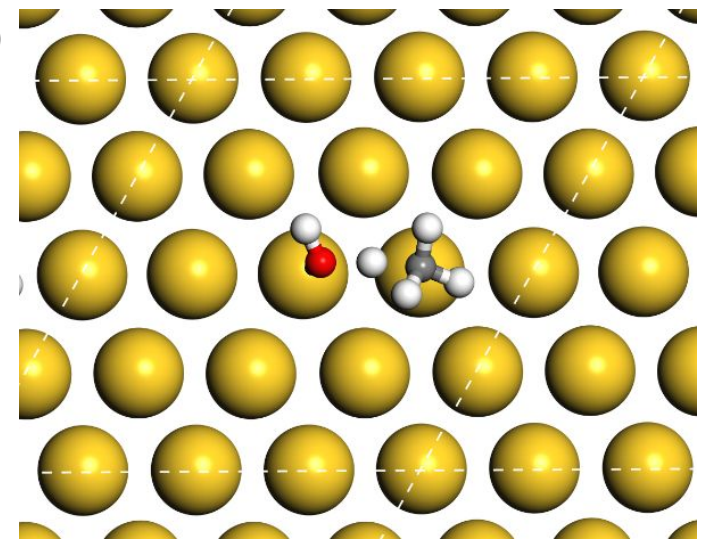

c)
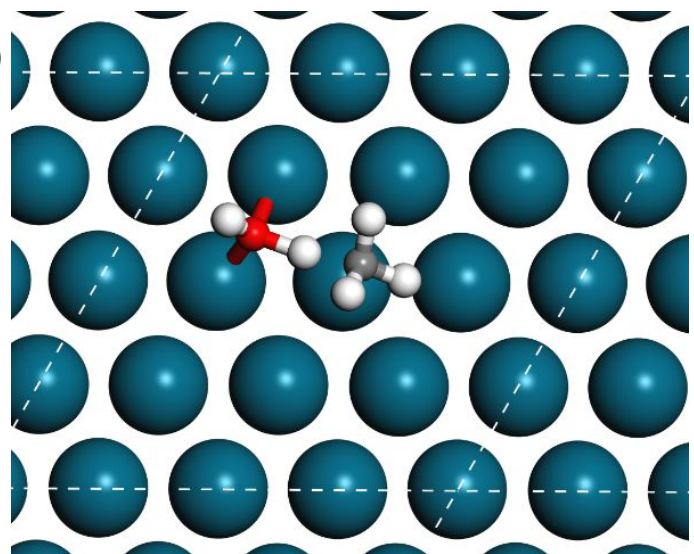

b)
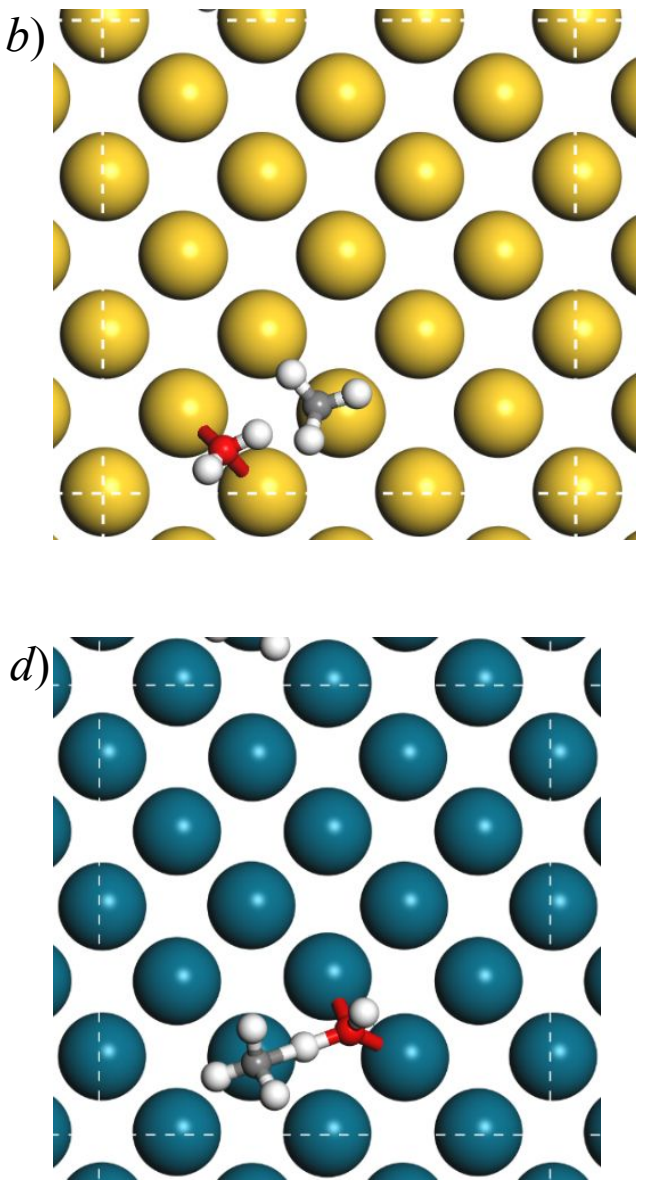

Figure S3: Transition states for the hydrogen abstraction from methane by a surface bound - OH(ads) radical on: $a$ ) $\mathrm{Au}(111)$ surface, $b) \operatorname{Au}(100)$ surface, $c) \operatorname{Pd}(111)$ surface, and $d$ ) $\operatorname{Pd}(100)$ surface.

Table S5: Bader charges for $\bullet \mathrm{OH}\left(\right.$ ads), the transferring $\mathrm{H}$ atom and $\bullet \mathrm{CH}_{3}$ (ads) in the transition state for hydrogen abstraction from methane by a surface bound $\cdot \mathrm{OH}(\mathrm{ads})$ radical.

\begin{tabular}{|c|c|c|c|c|c|}
\hline & $\begin{array}{c}q(\mathbf{O H}) \\
/|e|\end{array}$ & $\begin{array}{c}q(\mathbf{H}) \\
/|e|\end{array}$ & $\begin{array}{c}q\left(\mathrm{CH}_{3}\right) \\
/|\boldsymbol{e}|\end{array}$ & $\begin{array}{c}\mathrm{HO} . . . \mathrm{H}-\mathrm{CH}_{3}{ }^{a} \\
/ \AA\end{array}$ & ${ }_{/ \mathrm{HO}}^{\mathrm{HO}-\mathrm{CH}_{3}{ }^{a}}$ \\
\hline $\mathrm{Au}(111)$ & -0.482 & 0.398 & -0.227 & 1.313 & 1.348 \\
\hline $\mathrm{Au}(100)$ & -0.494 & 0.424 & -0.219 & 1.289 & 1.388 \\
\hline $\operatorname{Pd}(111)$ & -0.505 & 0.434 & -0.236 & 1.261 & 1.381 \\
\hline $\operatorname{Pd}(100)$ & -0.494 & 0.433 & -0.229 & 1.266 & 1.419 \\
\hline
\end{tabular}

Note: $a$ ) The inter-atomic distance that is measured is indicated by "...". 
a)

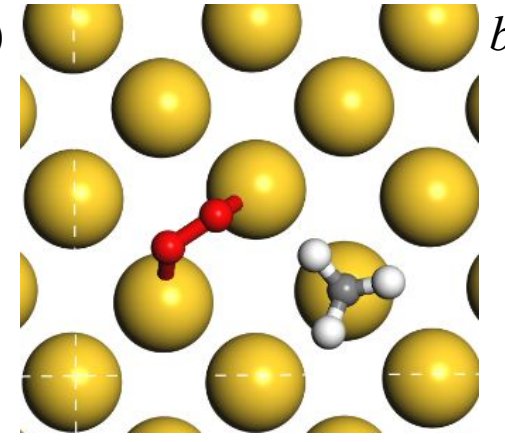

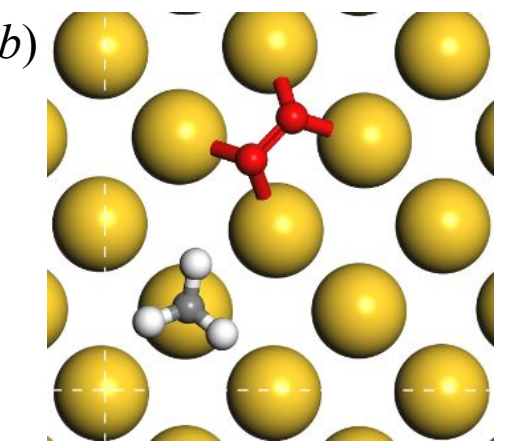

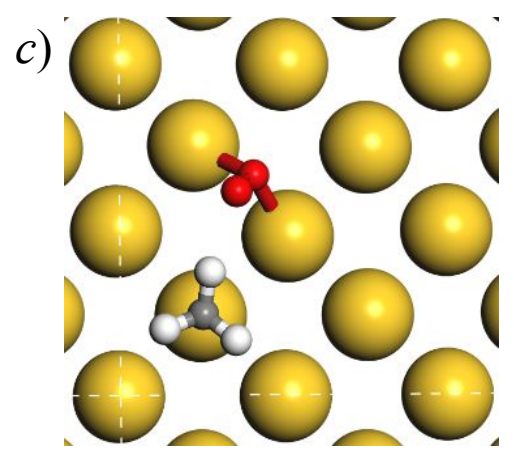

Figure S4: a) Configurations optimised for the $\cdot \mathrm{CH}_{3}(\mathrm{ads})+\mathrm{O}_{2}(\mathrm{ads})$ reaction $(\mathbf{4}$, Scheme 2$)$ for $\mathrm{Au}(100)$. Atom colours: Au; yellow, $\mathrm{C}$; grey, $\mathrm{O}$; red and $\mathrm{H}$; white.

Table S6: Bader charges for $\mathrm{Au}(100) \mathrm{O}_{2}$ (ads) $+\cdot \mathrm{CH}_{3}$ (ads).

\begin{tabular}{cccccc}
\hline $\begin{array}{c}\text { Au(100) } \\
\text { structure }\end{array}$ & $\begin{array}{c}\boldsymbol{q ( O 1 ) ^ { a }} \\
/|\boldsymbol{e}|\end{array}$ & $\begin{array}{c}\boldsymbol{q ( \mathbf { O } 2 ) ^ { \boldsymbol { a } }} \\
/|\boldsymbol{e}|\end{array}$ & $\begin{array}{c}\boldsymbol{q}\left(\mathbf{O}_{2}\right) \\
/|\boldsymbol{e}|\end{array}$ & $\begin{array}{c}\boldsymbol{q}\left(\mathrm{CH}_{3}\right) \\
/|\boldsymbol{e}|\end{array}$ & $\begin{array}{c}\mathbf{O}-\mathbf{O} \\
/ \AA\end{array}$ \\
\hline Fig. S4a & -0.294 & -0.296 & -0.590 & -0.023 & 1.344 \\
Fig. S4b & -0.402 & -0.391 & -0.793 & -0.025 & 1.423 \\
Fig. S4c & -0.282 & -0.188 & -0.470 & 0.000 & 1.302
\end{tabular}

Note: $a) \mathrm{O} 1$ is the oxygen closest to $\cdot \mathrm{CH}_{3}(\mathrm{ads})(\mathrm{Fig}$. $\mathrm{S} 4 \mathrm{a} / \mathrm{b})$ or in contact with the surface (Fig. S4c). 
a)

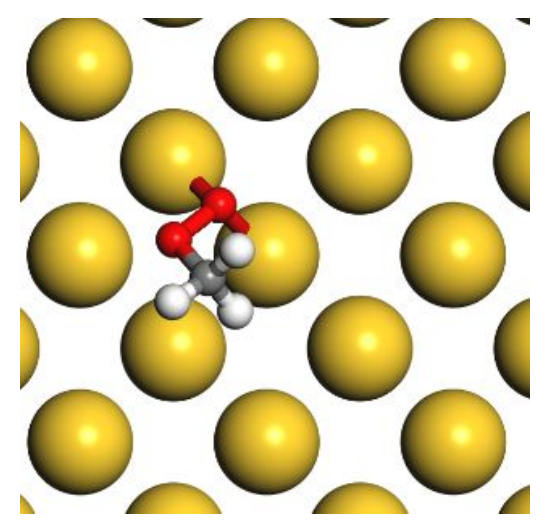

c)

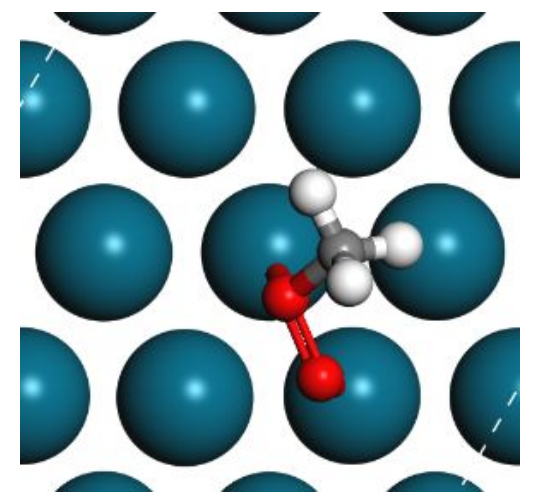

b)

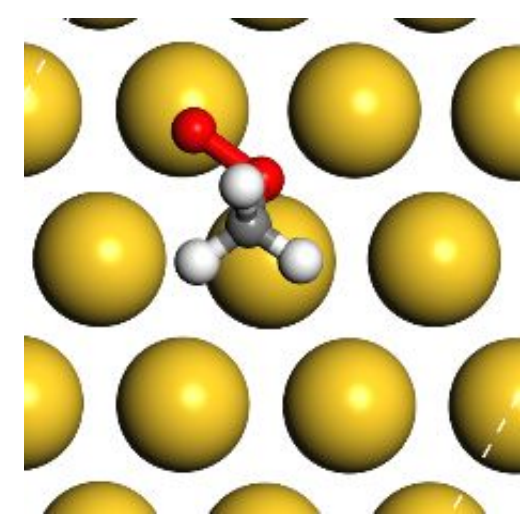

d)

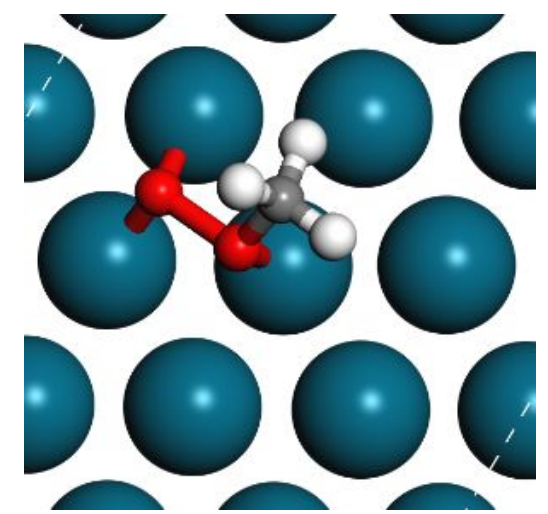

Figure S5: Configurations optimised for the $\mathrm{CH}_{3} \mathrm{O}_{2} \bullet$ (ads) intermediate, (5, Scheme 2) for $a) \mathrm{Au}(100)$ bridge, $b) \mathrm{Au}(111)$ top, c) $\mathrm{Pd}(111)$ top-top and d) $\mathrm{Pd}(111)$ top-bridge. Atom colours: $\mathrm{Au}$; yellow, $\mathrm{Pd}$; blue, $\mathrm{C}$; grey, $\mathrm{O}$; red and $\mathrm{H}$; white.

Table S7: Bader charges for $\mathrm{CH}_{3} \mathrm{O}_{2}$ (ads) for structures shown in Fig. S5.

\begin{tabular}{|c|c|c|c|c|}
\hline Structure & $\begin{array}{c}q(\mathbf{O 1})^{a} \\
/\left.|| e\right|^{2}\end{array}$ & $\begin{array}{c}q(\mathbf{O 2})^{a} \\
/|e|\end{array}$ & $\begin{array}{c}q\left(\mathrm{CH}_{3} \mathrm{O}_{2}\right) \\
/|\boldsymbol{e}|\end{array}$ & $\begin{array}{c}\mathbf{O}-\mathbf{O} \\
/ \AA \\
\end{array}$ \\
\hline $\mathrm{Au}(100)$ & -0.568 & -0.443 & -0.438 & 1.467 \\
\hline $\mathrm{Au}(111)$ & -0.569 & -0.406 & -0.401 & 1.454 \\
\hline $\operatorname{Pd}(111)$, Fig. S5c & -0.542 & -0.377 & -0.564 & 1.463 \\
\hline $\operatorname{Pd}(111)$, Fig. S5d & -0.630 & -0.455 & -0.489 & 1.667 \\
\hline
\end{tabular}

Note: a) $\mathrm{O} 1$ is the oxygen bonded to $\mathrm{C}, \mathrm{O} 2$ is the terminal oxygen atom. 
a)

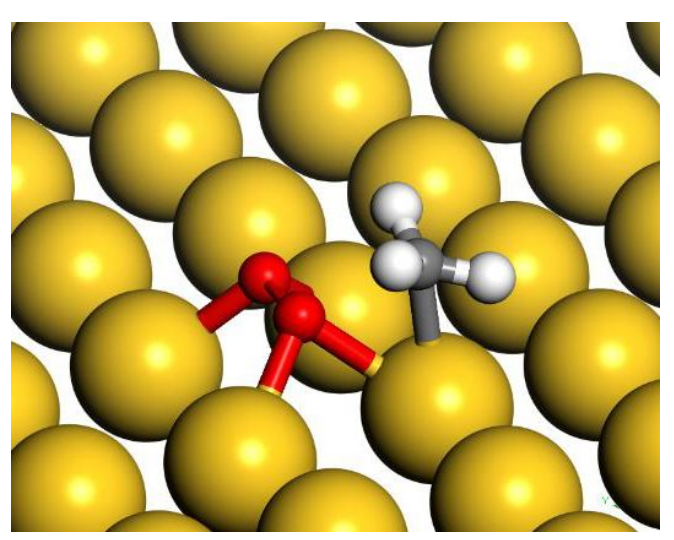

b)

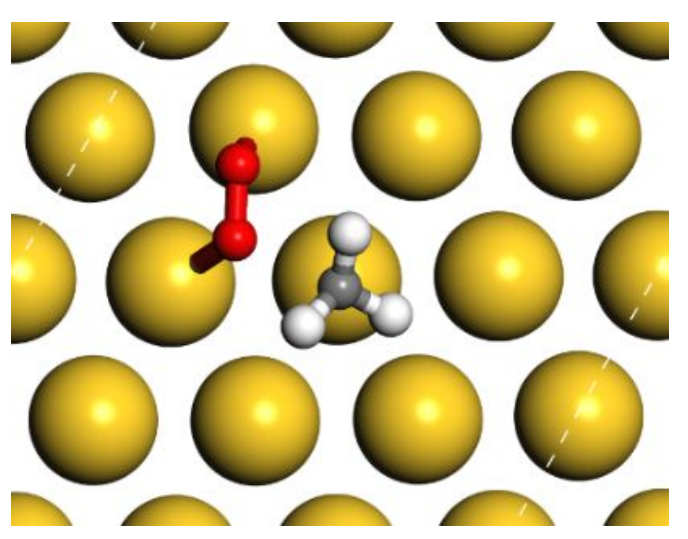

c)

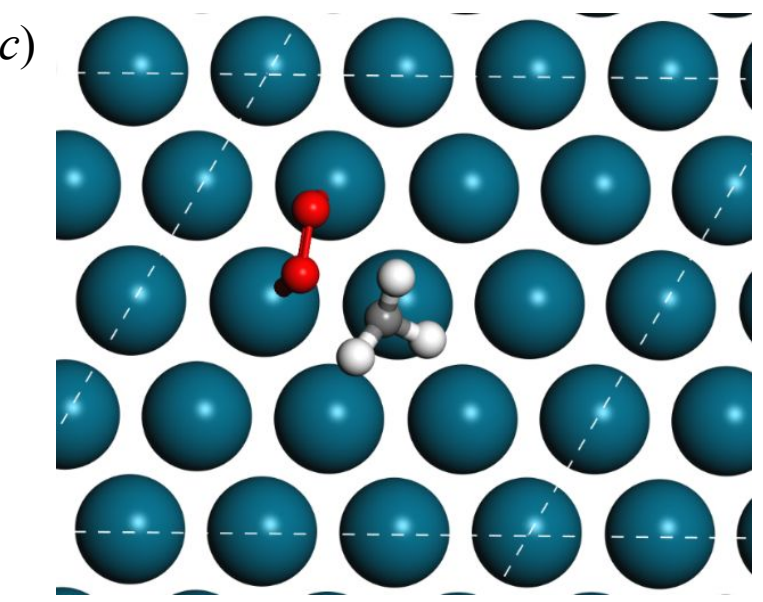

Figure S6: Optimised transition state structures for the formation of the $\mathrm{CH}_{3} \mathrm{OO} \bullet$ (ads) intermediate from adsorbed $\cdot \mathrm{CH}_{3}$ (ads) and $\mathrm{O}_{2}$ (ads), (step $\mathbf{4} \rightarrow \mathbf{5}$, Scheme 2) for a) $\mathrm{Au}(100), b) \mathrm{Au}(111)$, and c) $\mathrm{Pd}(111)$. Atom colours: Au; yellow, Pd; blue, C; grey, $\mathrm{O}$; red and $\mathrm{H}$; white.

Table S8: Bader charges for $\mathrm{CH}_{3}\left(\right.$ ads) and $\mathrm{O}_{2}$ (ads) for structures shown in Fig. S6.

\begin{tabular}{cccc}
\hline Structure & $\begin{array}{c}\boldsymbol{q}\left(\mathbf{O}_{2}\right) \\
/|\boldsymbol{e}|\end{array}$ & $\begin{array}{c}\boldsymbol{q}\left(\mathbf{C H}_{3}\right) \\
/|\boldsymbol{e}|\end{array}$ & $\begin{array}{c}\mathbf{O}-\mathbf{O} \\
/ \AA\end{array}$ \\
\hline $\mathrm{Au}(100)$ & -0.709 & 0.189 & 1.391 \\
$\mathrm{Au}(111)$ & -0.509 & 0.120 & 1.319 \\
$\mathrm{Pd}(111)$ & -0.564 & 0.169 & 1.364 \\
\hline
\end{tabular}


a)

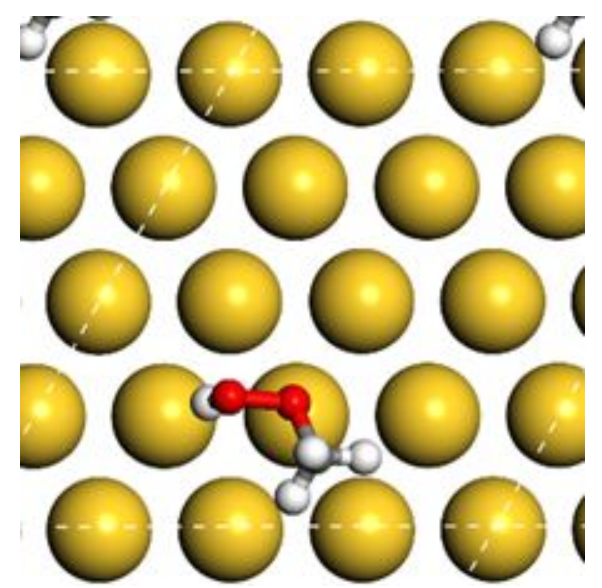

c)

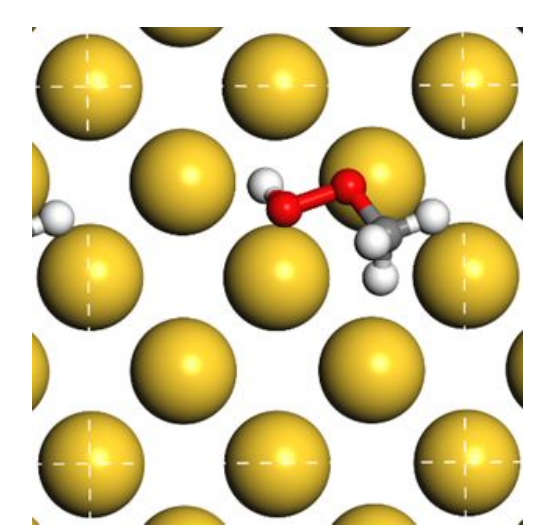

e)

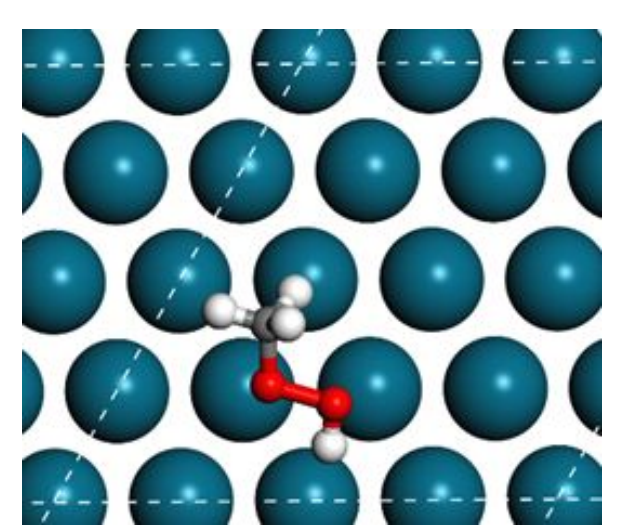

g)

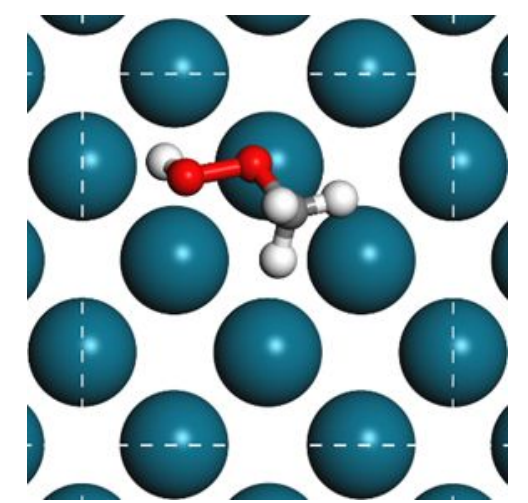

b)

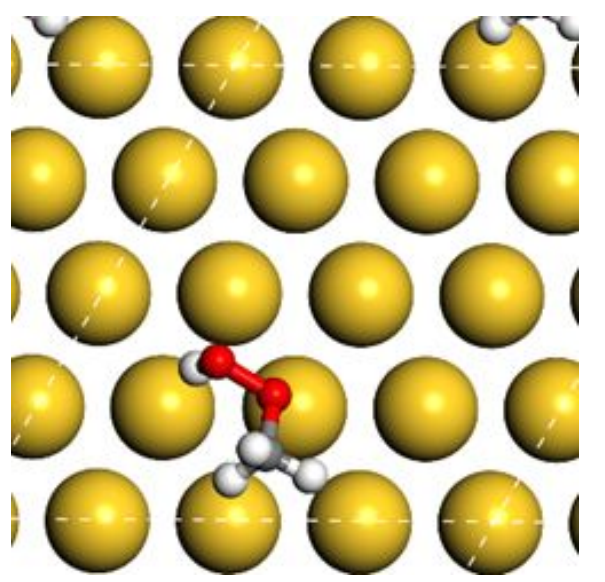

d)

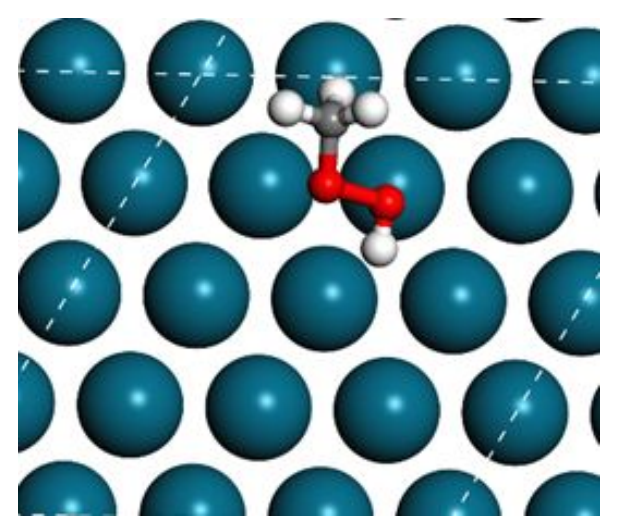

f)

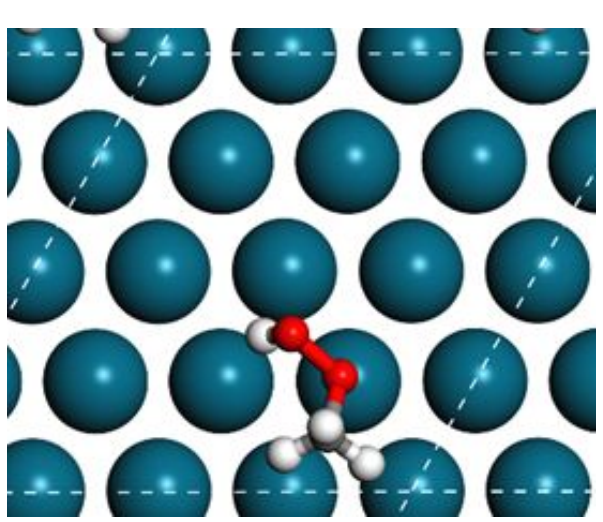

h)

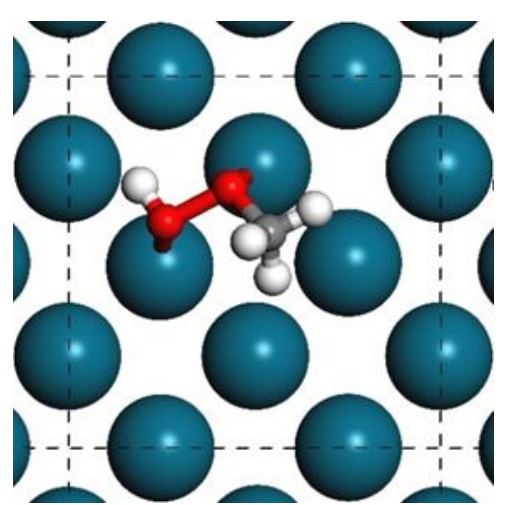

Figure S7: Optimised structures of $\mathrm{CH}_{3} \mathrm{OOH}(\mathrm{ads})$ on $a$ ) $\mathrm{Au}(111)$ /top-bridge,

b) $\mathrm{Au}(111) /$ top-hollow, c) $\mathrm{Au}(100) /$ top-hollow, $d$ ) $\mathrm{Pd}(111) /$ top-bridge, $e$ ) $\mathrm{Pd}(111) /$ top-top, f) $\operatorname{Pd}(111) /$ top-hollow, g) $\operatorname{Pd}(100) /$ top-hollow and $h) \operatorname{Pd}(100) /$ top-top.

Atom colours: $\mathrm{Au}$; yellow, $\mathrm{Pd}$; blue, $\mathrm{C}$; grey, $\mathrm{O}$; red and $\mathrm{H}$; white. 
Table S8: Bader charges for $\mathrm{O}_{2}$ (ads) for structures shown in Fig. 8.

\begin{tabular}{lcc}
\hline \multicolumn{1}{c}{ Structure } & $\begin{array}{c}\boldsymbol{q}\left(\mathbf{O}_{2}\right) \\
/|\boldsymbol{e}|\end{array}$ & $\begin{array}{c}\mathbf{O}-\mathbf{O} \\
/ \AA\end{array}$ \\
\hline $\mathrm{Au}_{1} \mathrm{Pd}_{17}(100) /$ bridge-bridge & -0.685 & 1.406 \\
$\mathrm{Au}_{1} \mathrm{Pd}_{15}(111) /$ top-bridge & -0.567 & 1.357 \\
$\mathrm{Au}_{1} \mathrm{Pd}_{15}(111) /$ top-top & -0.464 & 1.332 \\
\hline
\end{tabular}

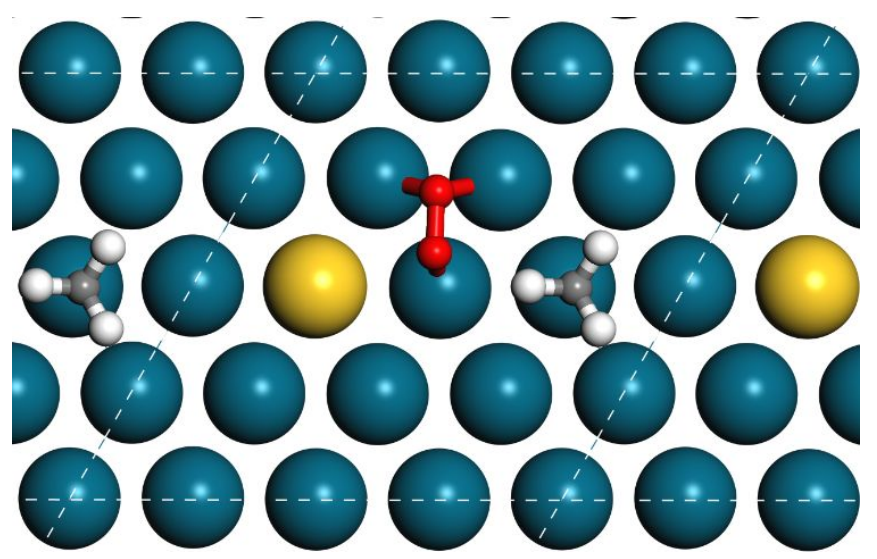

Figure S8: Optimised structures of co-adsorbed $\bullet \mathrm{CH}_{3}$ (ads) $+\mathrm{O}_{2}$ (ads) used as a start point for $\cdot \mathrm{CH}_{3}(\mathrm{ads})$ on the $\mathrm{Au}_{1} \mathrm{Pd}_{15}(111)$ surface. Atom colours: $\mathrm{Au}$; yellow, $\mathrm{Pd}$; blue, $\mathrm{C}$; grey, $\mathrm{O}$; red and $\mathrm{H}$; white. 
a)

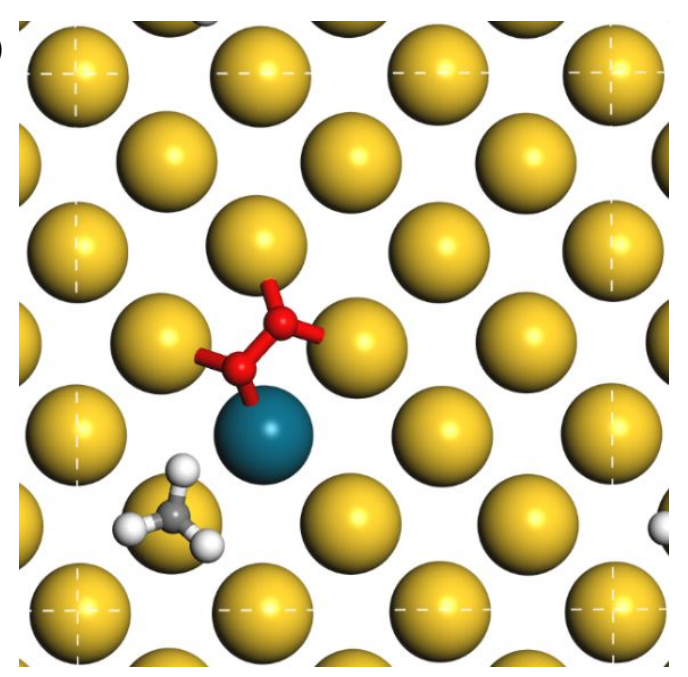

c)

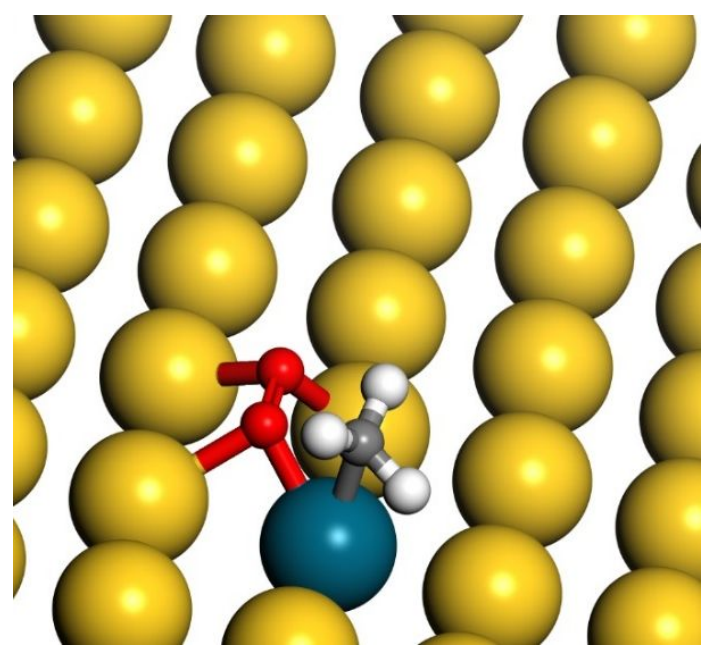

b)

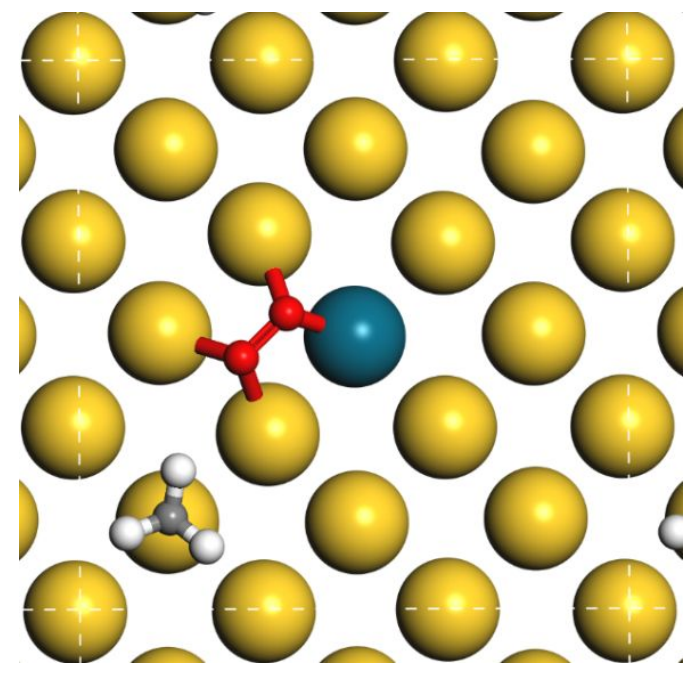

d)

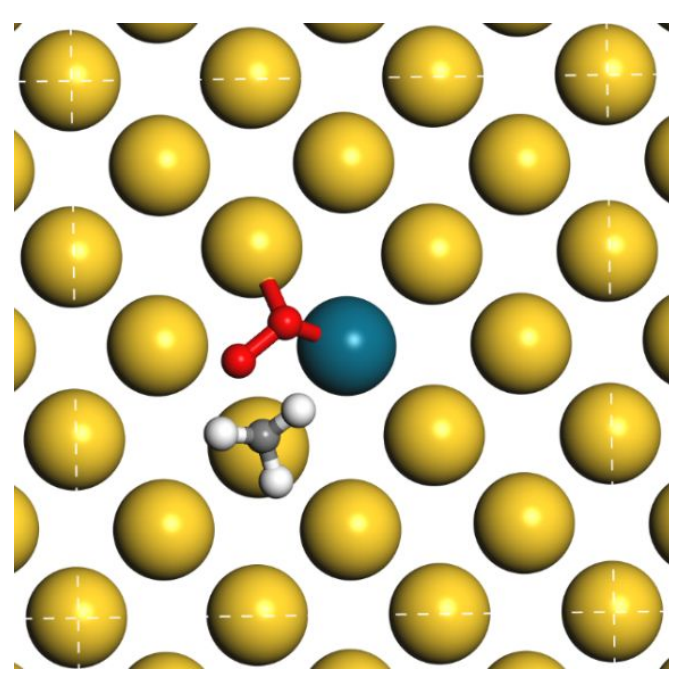

Figure S9: Optimised structures of co-adsorbed $\bullet \mathrm{CH}_{3}(\mathrm{ads})+\mathrm{O}_{2}$ (ads) on the $\mathrm{Au}_{17} \mathrm{Pd}_{1}(100)$ surface, $a$ ) with $\mathrm{Pd}$ atom and $b$ ) with $\mathrm{Au}$ of $\mathrm{O}_{2}(\mathrm{ads})$ position neighbouring the methyl radical adsorption site, and calculated transition state for the formation of $\mathrm{CH}_{3} \mathrm{O}_{2} \bullet$ (ads) with $c$ ) the $\mathrm{H}_{3} \mathrm{C} . . \mathrm{O}_{2}$ bond formed at $\mathrm{Pd}$ and $d$ ) the $\mathrm{H}_{3} \mathrm{C} . . \mathrm{O}_{2}$ bond formed at Au. Atom colours: Au; yellow, $\mathrm{Pd}$; blue, $\mathrm{C}$; grey, $\mathrm{O}$; red and $\mathrm{H}$; white. 


\section{References}

(1) Bader, R. F. W.; Matta, C. F. Atoms in Molecules as Non-Overlapping, Bounded, Space-Filling Open Quantum Systems. Found Chem 2013, 15 (3), 253-276. https://doi.org/10.1007/s10698-012-9153-1.

(2) Henkelman, G.; Arnaldsson, A.; Jónsson, H. A Fast and Robust Algorithm for Bader Decomposition of Charge Density. Computational Materials Science 2006, 36 (3), 354-360. https://doi.org/10.1016/j.commatsci.2005.04.010.

(3) Sanville, E.; Kenny, S. D.; Smith, R.; Henkelman, G. Improved Grid-Based Algorithm for Bader Charge Allocation. J. Comput. Chem. 2007, 28 (5), 899908. https://doi.org/10.1002/jcc.20575.

(4) Tang, W.; Sanville, E.; Henkelman, G. A Grid-Based Bader Analysis Algorithm without Lattice Bias. J. Phys.: Condens. Matter 2009, 21 (8), 084204. https://doi.org/10.1088/0953-8984/21/8/084204. 